\title{
Optimization of maltodextrin and carrageenan gum concentration added in spray drying process of Pouzolzia zeylanica extract by response surface methodology
}

\author{
Tan, D. Nguyen ${ }^{1 *}, \&$ Thuy, M. Nguyen ${ }^{2}$ \\ ${ }^{1}$ Department of Food Technology, An Giang University, An Giang, Vietnam \\ ${ }^{2}$ Department of Food Technology, Can Tho University, Can Tho, Vietnam
}

ARTICLE INFO
Research paper
Received: January 02, 2018
Revised: April 20, 2018
Accepted: May 24, 2018
Keywords
Carrageenan
Maltodextrin
Pouzolzia zeylanica
Response Surface Methodology
Spray drying

${ }^{*}$ Corresponding author

Nguyen Duy Tan

Email: ndtan@agu.edu.vn

\begin{abstract}
Pouzolzia zeylanica is a kind of medicinal plant which is generally cultivated in Mekong Delta region. It owns many bioactive compounds that are known to possess antioxidant, antimicrobial and anticarcinogenic properties. This study aimed to optimize additional carrier concentration for spray drying of Pouzolzia zeylanica extract. Response Surface Methodology (RSM) with central composite design (CCD) was applied for optimization and investigation of the influence of maltodextrin $(5 \div 15 \%, \mathrm{w} / \mathrm{v})$ and carrageenan gum $(0.06 \div 1.0 \%, \mathrm{w} / \mathrm{v})$ concentration on the physicochemical characteristics of spray dried powder (bioactive compounds, moisture content as well as particle size distribution). The results showed that the optimum concentrations of maltodextrin and carrageenan gum were $8.8 \% \mathrm{w} / \mathrm{v}$ and $0.082 \% \mathrm{w} / \mathrm{v}$, respectively. At these optimal conditions, the anthocyanin, flavonoid, polyphenol, tannin, moisture content and particle size of obtained spray dried powder were $5.77 \mathrm{mg}$ cyanidin-3-glycoside equivalents $(\mathrm{CE}) / 100 \mathrm{~g}$; $29.49 \mathrm{mg}$ quercetin equivalents $(\mathrm{QE}) / \mathrm{g} ; 28.35 \mathrm{mg}$ gallic acid equivalents (GAE)/g; $27.44 \mathrm{mg}$ tannic acid equivalents (TAE)/g, 6.55\% and 6.09 $\mu \mathrm{m}$, respectively.
\end{abstract}

Cited as: Nguyen, T. D., \& Nguyen, T. M. (2018). Optimization of maltodextrin and carrageenan gum concentration added in spray drying process of Pouzolzia zeylanica extract by response surface methodology. The Journal of Agriculture and Development 17(3), 77-85.

\section{Introduction}

In recent years, there has been growing interest in alternative therapies and the therapeutic use of natural products and in the last decade much attention has been shifted to search for phytochemicals of native and naturalized plants for pharmaceutical and nutritional purposes (Oktay et al., 2003; Wangensteen et al., 2004). Pouzolzia zeylanica was reported that it had no oral acute toxicity at the oral dose of $10 \mathrm{~g}$ extract powder $/ \mathrm{kg}$ (Tran et al., 2010) and can be used to treat cough, pulmonary tuberculosis, sore throat, enteristis and dysentery (Vo, 2012). Many researches showed that this plant contains flavonoids, tannin, carotenoids, quercetin, vitexin, isovitexin, phylanthin, metyl- sterate, $\beta$-sitosterol, oleanolic acid, epicatechin, scopolin, apigenin, alkaloids, steroids, glycosides and saponins (Ghani, 2003; Le, 2007; Fu et al., 2012; Saha \& Paul, 2012). Therefore, it will be an important material source for processing functional products as beverage, instant tea, etc.

Spray drying is one of the most commonly used techniques in transforming a large amount of liquid foods into powder form, due to commercially costs and final product quality and stability (Favano et al., 2010). Food powders have many benefits and economic potential over their liquid forms such as volume reduction and packaging easier handling and transportation, stable structure and much longer shelf life (Sarabandi et al., 2014). The physicochemical properties of spraydried powders depend on the process variables 
such as the characteristic of liquid feed including viscosity, flow rate and the drying air in term of pressure and temperature as well as the type of atomizer (Tee et al., 2012). In order to achieve a successful drying process, high molecular weight of drying agent such as maltodextrin, gum needed to be used for reducing stickiness and wall deposition in the dryer chamber. Moreover, the drying carrier agent may improve powder recovery and production yield (Goula \& Adamopoulos, 2005; Langrish et al., 2007; Martineli et al., 2007).

The objective of this study was to evaluate the impact of maltodextrin and carrageenan gum concentration added to spray drying process of Pouzolzia zeylanica extract on the anthocyanin, flavonoid, polyphenol, tannin, moisture content and particle size distribution of dried powder product. The other variables of spray drying process were maintained constant.

\section{Materials and Methods}

\subsection{Sample preparation}

Pouzolzia zeylanica plants were collected in March 2015 from An Giang University. They were harvested after one and a half month cultivation, with $20-30 \mathrm{~cm}$ in height. The plants were then washed with tap-water, air-dried until the final moisture content about $12 \%$, cut into small pieces with the length of about $2-3 \mathrm{~cm}$, were extracted with water using airtight extractor. The stirring rate, temperature, time and ratio of solvant and raw material of extraction process were maintained in $90 \mathrm{rpm}, 81^{\circ} \mathrm{C}, 30 \mathrm{~min}$ and $27: 1 \mathrm{v} / \mathrm{w}$, respectively. The hot extract was filtered through cotton cloth and their quantity was determined. The extract was next blended with maltodextrin and carrageenan gum at different concentration following experimental design before spray drying process. The inlet hot air temperature and feed flow speed of spray drying process were $180^{\circ} \mathrm{C}$ and $18 \mathrm{rpm}$, respectively. Drying process was carried out in a laboratory scale spray dryer (SD-05, LabPlant $^{\text {TM }}$, United Kingdom), with co-current flow regime, the flow rate of drying air was fixed at $60 \mathrm{~m}^{3} \mathrm{~h}^{-1}$ and the atomizing air was 1.1 bar.

\subsection{Powder product analysis}

Physical characteristics: residual moisture content and total content solids of the product were measured using the infrared humidity analyzer (model AND MS-50, Japan). The particle size of the different samples were obtained in the particle analyzer (model ZEOL-5500, Japan).

Bioactive compounds: the anthocyanin content was determined by using the $\mathrm{pH}$ differential method (Ahmed et al., 2005; Santos et al., 2013). The results were expressed as mg cyanidin3 -glycoside equivalents (CE) per gram product. The aluminum chloride colorimetric method was used for flavonoids determination and the amount of flavonoid was calculated as quercetin equivalent (QE) per gram of product (Eswari et al., 2013; Mandal et al., 2013). The polyphenol content was determined by Folin-Ciocalteu reagent method and the results were expressed as milligrams of gallic acid equivalents (GAE) per gram of product (Hossain et al., 2013). Tannin content was determined by Folin-Denis method and the results were showed as milligrams of tannic acid equivalents (TAE) per gram of product (Laitonjam et al., 2013).

\subsection{Experimental design and data analysis}

In order to evaluate the effect of maltodextrin (5 to $15 \%, \mathrm{w} / \mathrm{v})$ and carrageenan gum (0.06 to $0.10 \%, \mathrm{w} / \mathrm{v})$ concentration on moisture content, particle size distribution and bioactive compounds (anthocyanin, flavonoid, polyphenol and tannin content), a full factorial design $\left(3^{2}\right)$ was applied with five replicates in the center point of the experiment design to fit the surface plot for the responses and to estimate the pure error of the multiple regression models, totaling 13 sample preparations (Table 1). The experimental design and statistical analysis were performed using Statgraphics Plus version 15.0 (SYSTAT Software Inc., Richmond, CA, USA) (Myers et al., 2009). A quadratic equation (second degree polynomial equation) was used to fit the results:

$$
\begin{aligned}
\mathrm{Y}=\beta_{0} & +\sum_{i=1}^{k} \beta_{i} \mathrm{X}_{i}+\sum_{i=1}^{k} \beta_{i i} \mathrm{X}_{i}^{2} \\
& +\sum_{i=1}^{k-1} \sum_{j=2}^{k} \beta_{i j} \mathrm{X}_{i} \mathrm{X}_{j} \quad(i<j)
\end{aligned}
$$

Where $\mathrm{Y}$ is the predicted response parameter, $\beta_{0}$ is a constant, $\beta_{i}, \beta_{i i}$ and $\beta_{i j}$ are the regression coefficients. $\mathrm{X}_{i}$ and $\mathrm{X}_{j}$ are the levels of the independent variables (maltodextrin and carrageenan gum concentration). Experimental data 
were then fitted to the selected regression model to get a clear understanding of the correlation between each factor and different responses. This was obtained by estimating the numerical values of the model term (regression coefficients), whose significance was statistically judged in accordance with t-statistic at confidence interval of $95 \%$. Non-significant $(P>0.05)$ term was deleted from the initial equation and data were refitted to the selected model. The quality of the mathematical models fitted by RSM was evaluated by ANOVA, based on the F-test, the probability value $\left(\mathrm{P}_{\text {value }}\right)$ of lack-of-fit and on the percentage of total explained variance $\left(\mathrm{R}^{2}\right)$ and also on the adjusted determination coefficient $\left(\mathrm{R}_{\text {adj }}^{2}\right)$, which provide a measurement of how much of the variability in the observed response values could be explained by the experimental factors and their linear and quadratic interactions (Table 2). A simultaneous optimization using the desirability function was performed in order to maximize the anthocyanin, flavonoid, polyphenol, tannin content and to minimize moisture content and particle size distribution.

\section{Results and Discussion}

\subsection{Effect of matodextin and carragennan concentration on bioactive compounds}

In spray drying processing, bioactive compounds can be often destroyed by thermal air. Thus, the supply of maltodextrin and carrageenan gum into Pouzolzia zeylanica extract to reduce bioactive compounds damage and improve physicochemical characteristics of obtained powder by gel particle formation mechanisms of polysaccharide to protect bioactive compounds during spray drying process (Burey et al., 2008) (Figure 1).
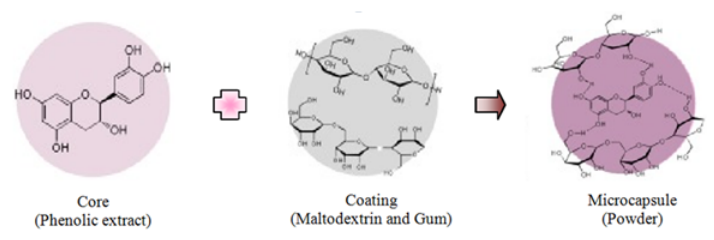

Figure 1. Schematic of gel particle formation mechanisms.

The result showed that anthocyanin, flavonoid, polyphenol and tannin content changed from 2.42 to $5.85 \mathrm{mg} \mathrm{CE} / 100 \mathrm{~g} ; 20.63$ to $29.30 \mathrm{mg} \mathrm{QE} / \mathrm{g}$;
27.39 to $28.35 \mathrm{mg} \mathrm{GAE} / \mathrm{g}$ and 25.83 to $27.43 \mathrm{mg}$ TAE/g powder product (Table 1 ), respectively. The bioactive compounds were presented in final products which depended on the supplemental carrier percent of maltodextrin and carrageenan.

The concentration of carrageenan gum and maltodextrin had a positive quadratic effect $(P<$ 0.01 ) on anthocyanin content. The anthocyanin content increased with increasing carrageenan gum concentration in approximately 0.075 to $0.095 \%(\mathrm{w} / \mathrm{v})$ and achieved optimal values at $0.083 \%$. Besides, anthocyanin content was also achieved high values in maltodextrin concentration approximately 7 to $10 \%(\mathrm{w} / \mathrm{v})$ and reached an optimum of $8.88 \%$ (Figure 2a). It could be noticed in Figure 2b that levels of carrageenan gum had slight quadratic influence $(P<0.05)$ to flavonoid content in product. The flavonoid content achieved high values with carrageenan gum concentration of range from 0.065 to $0.10 \%$ $(\mathrm{w} / \mathrm{v})$ and reached optimum values in the carrageenan gum concentration of $0.082 \%$. Whereas the concentration of maltodextrin had a clear quadratic impact $(P<0.01)$ on flavonoid content in product. The flavonoid content achieved high values in maltodextrin concentration from 5 to $9 \%(\mathrm{w} / \mathrm{v})$ and the optimum values obtained at maltodextrin concentration of $7.38 \%$. The carrageenan gum concentration had slight quadratic impact $(P<0.05)$ on the polyphenol content in the product. However, the maltodextrin levels had significant quadratic effect on polyphenol content $(P<0.01)$. The high polyphenol content was obtained when using the carrageenan gum concentration from 0.07 to $0.10 \%(\mathrm{w} / \mathrm{v}$ ) and optimal values was achieved at $0.086 \%$. In addition, the polyphenol content increased with maltodextrin concentration increases in the range from 5 to $11 \%(\mathrm{w} / \mathrm{v})$ and the optimum value was found at $6.83 \%$ of maltodextrin concentration (Figure 2c). The response surface and contour plot in Figure $2 \mathrm{~d}$ showed that carrageenan gum concentration had significant quadratic influence $(P<0.01)$ on tannin content in the product, whereas the maltodextrin levels had slight quadratic effect on tannin content.

A high tannin content was obtained when using carrageenan gum concentration from 0.07 to $0.095 \%(\mathrm{w} / \mathrm{v})$ and the highest value was achieved at $0.084 \%$ of carrageenan gum. Moreover, the high tannin content was obtained when using the maltodextrin percent ranging from 5 to $15 \%$ 


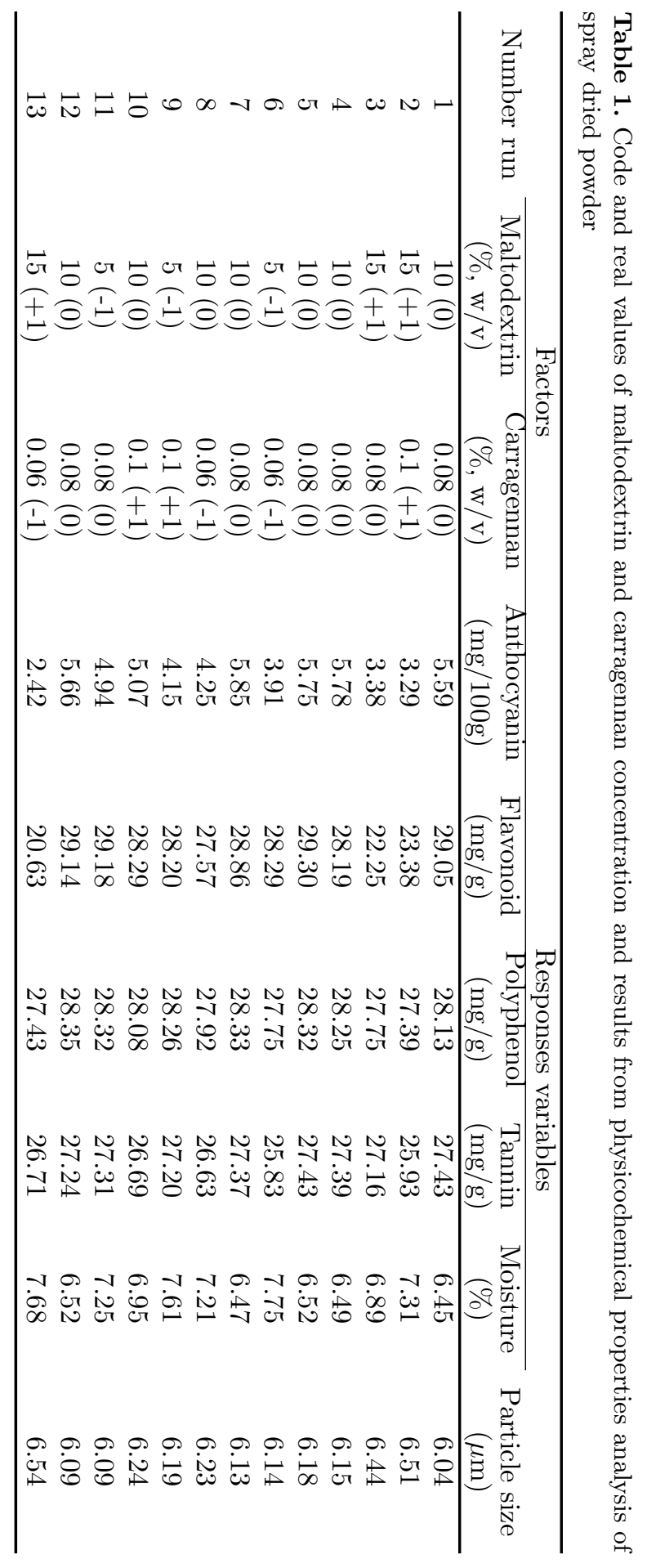




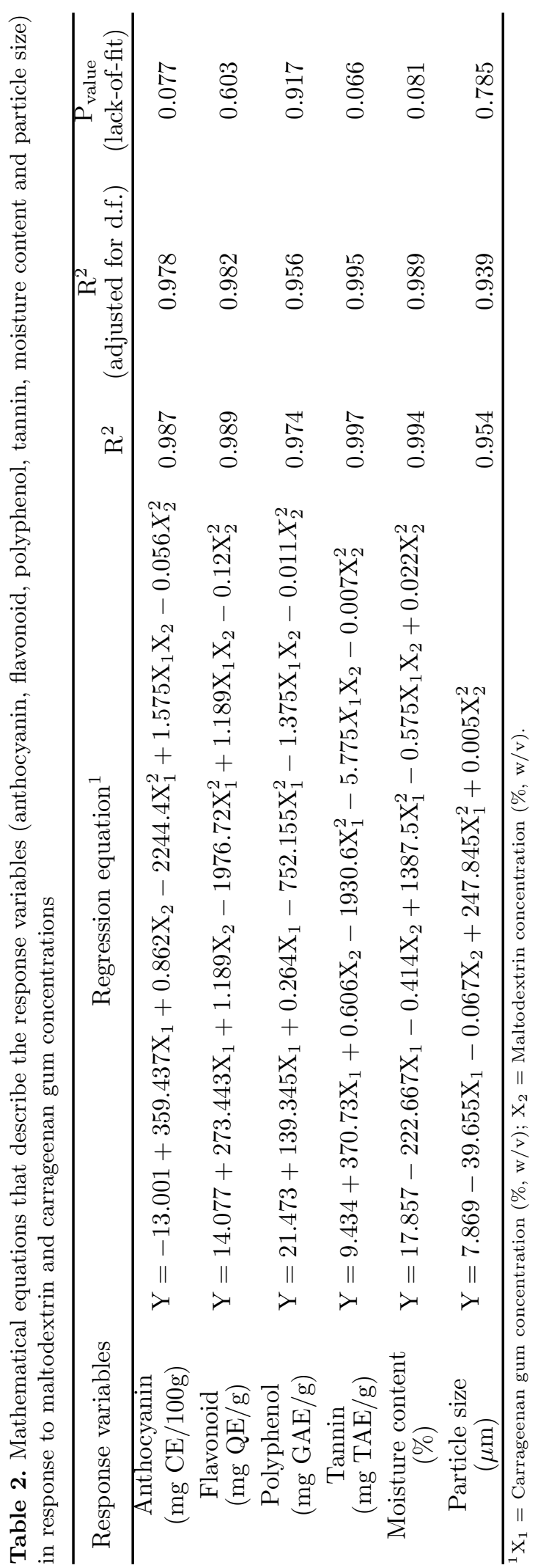




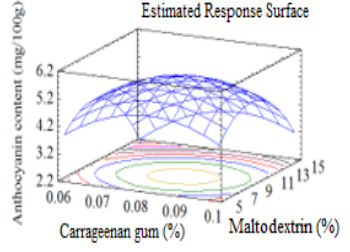

(a)

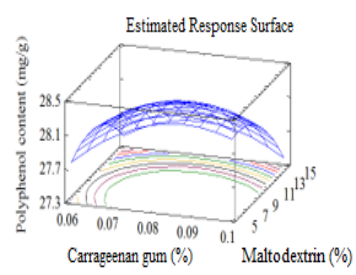

(c)

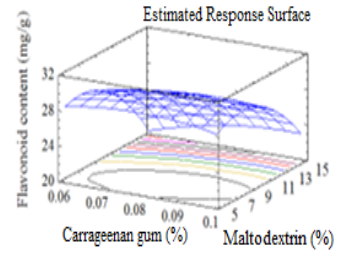

(b)

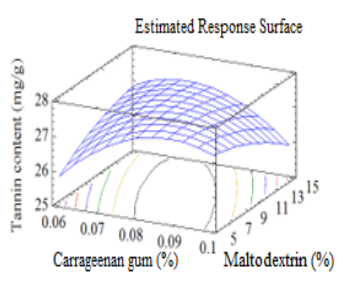

(d)
Figure 2. Response surface and contour plots for anthocyanin (a), flavonoid (b), polyphenol (c) and tannin $(d)$ content in different maltodextrin and carrageenan gum concentrations.

$(\mathrm{w} / \mathrm{v})$ and an optimum value was found at maltodextrin concentration was $8.19 \%$.

The content of compounds (anthocyanin, flavonoid, polyphenol and tannin) increased with increasing the maltodextrin concentration from 5 to $9 \%$ and this compound content decreased when using maltodextrin from 9 to $15 \%$.

The maltodextrin and carrageenan gum concentrations were significant quadratic impact on bioactive compounds in product. The bioactive compounds achieved the high values when the concentrations of maltodextrin and carrageenan gum were added to the extract in the range from 6.8 to $8.8 \%$ and 0.082 to $0.086 \%$, respectively. Bhusari \& Kumar (2014) also showed the polyphenol content was increased when increasing the concentration of added carrier agent. Maasniza et al. (2013) reported that the best quality of Garcinia powder with additional maltodextrin concentration was $5 \%$. The beetrootorange juice powder was also obtained with the best functional properties and the conservation of betalain was high when using $5 \%$ of maltodextrin (Ochoa-Martinez et al., 2015). The best quality of Ber powder was obtained with encapsulating material, with $8 \%$ maltodextrin (Singh et al., 2014), whereas the use of maltodextrin/pectin with 10:1 ratio $(11 \% \mathrm{w} / \mathrm{v})$ led to encapsulate $3 \% \mathrm{w} / \mathrm{v}$ polyphenol-rich extract forming a stable powder made up of well-formed and micronized particles suitable for storage and handling (San- sone et al., 2011). The pink guava powder produced with $15 \%$ of maltodextrin was found to be more convenient than other concentrations. The obtained powder had a low moisture content and was more stable with the highest bulk density (Shishir et al., 2015). The obtained pequi pulp powder with high nutritional quality (vitamin C, carotenoid) found at additional maltodextin concentration was 18\% (Santana et al., 2016).

\subsection{Effect of maltodextrin and carragennan concentration on moisture content and particle size of powder product}

The moisture content had an influence on the quality of the powder (Goula et al., 2004). The results in Figure 3a showed that the additional carriers concentration also had significant quadratic impact on the moisture content of spray dried powder product $(P<0.01)$. The moisture content was decreased in increasing maltodextrin and carrageenan gum concentration. The low moisture content was obtained when using maltodextrin and carrageenan gum at concentration varied from 9 to $12 \%$ and 0.075 to $0.09 \%$, respectively. The lowest moisture content was achieved at maltodextrin of $10.59 \%$ and carrageenan gum of $0.082 \%$. The study result was also similar to the result reported of Fernandes et al. (2012), Wang \& Zhou (2013), \& Sabhadinde (2014). The concentration of maltodextrin used for development of the Pouzolzia zeylanica powder varied between 5 to $15 \%(\mathrm{w} / \mathrm{v})$. The maltodextrin concentration using in this study was less than 10 to $30 \%$ that were used by Abadio et al. (2004), Tonon et al. (2008), \& Kha et al. (2010). Moisture content of sample decreased with increasing maltodextrin concentration from 5 to $9 \%$. Abadio et al. (2004) also found a decrease in moisture content in final pineapple juice powder with an increase of the maltodextrin concentration from 10 to $15 \%(\mathrm{w} / \mathrm{v})$. A higher concentration of maltodextrin used could increase the concentration of feed solids and could reduce the content of total moisture for evaporation (Grabowski et al., 2006). Carrageenan gum concentration had no effect on particle size with $P<0.05$. The mean particle size was increased with increasing the maltodextrin concentration (Figure $3 \mathrm{~b}$ ). The result from Sharifi et al. (2015) revealed that concentration of maltodextrin increased from 7.5 to $15 \%$, SEM micrographs of the powder indicated the increasing trend in particle size as a result of in- 


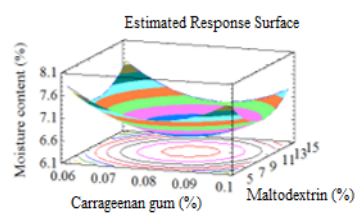

(a)

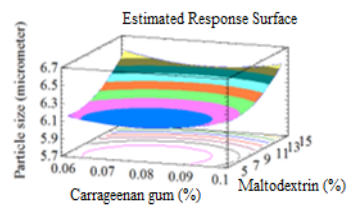

(b)

Figure 3. Response surface and contour plots for moisture content (a) and particle size (b) in different maltodextrin and carrageenan gum concentrations.

crease of concentration of maltodextrin as drying aid. However, Fernandes et al. (2012) reported that no correlation was found between particle size distribution and different carbohydrate concentration.

A statistical analysis was performed on the experimental results to obtain the regression models. ANOVA was used to evaluate the significance of each variable on the model. The quadratic model for all the response in terms of coded factors are shown in Table 2. The goodness-of-fit of the regression model showed that the experiment and predicted data were fitted and the coefficient of determination $\mathrm{R}^{2}>0.8$ (Guan et al., 2008). In addition, the probability value of lack-of-fit was non-significant $(P>0.05)$ (Zabeti et al., 2009). The results of ANOVA analysis showed that the linear, quadratic and interaction factors of maltodextrin and carrageenan gum concentration had effects on anthocyanin, flavonoid, polyphenol, tannin and moisture content of obtained powder product with the reliability of $95 \%$. However, the carrageenan levels were not effective on particle size, so regression equation of particle size did not have interaction factor of carrageenan gum and maltodextrin concentration. The coefficient of determination of the predicted models in the response was $\mathrm{R}^{2}>0.954, \mathrm{R}_{\text {adj }}^{2}>0.939$ and lack of fit had $P>$ 0.05 . These values would give a relatively good fit to the mathematic model. Moreover, the correlation between experimental and predictable data of goal functions such as anthocyanin, flavonoid, polyphenol, tannin, moisture content and particle size are also shown in Figure 4.

\subsection{Multiple response optimization}

The simultaneous optimization of multiple responses might be a main concern for industrial applications (Tsai et al., 2010). The energy cost of the process significantly diminished when ex-
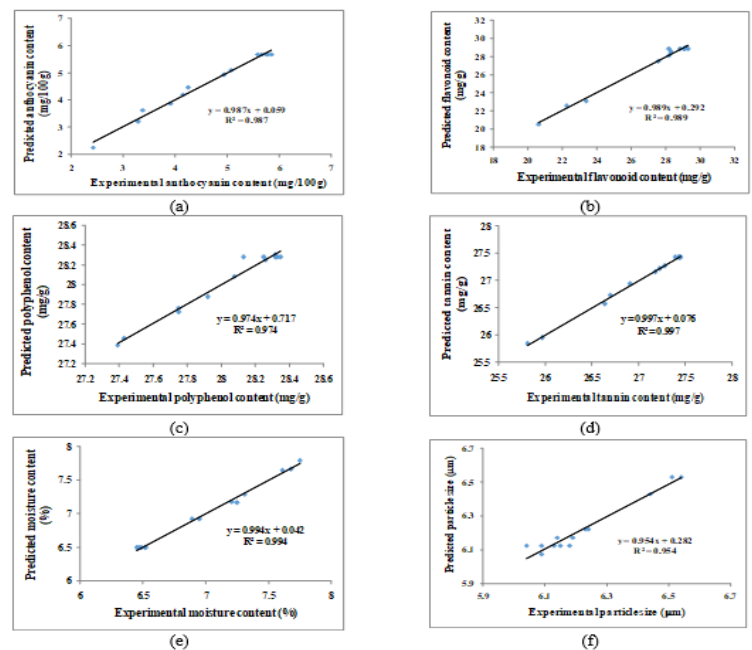

Figure 4. Correlation between the experimentally and the estimated values for anthocyanin (a), flavonoid (b), polyphenol (c), tannin (d), moisture content (e) and particle size (f) using the models described in equation $2,3,4,5,6,7$, respectively (as shown in Table 2).

traction parameters were optimized (Spigno et al., 2007). The response variables including anthocyanin, flavonoid, polyphenol, tannin, moisture content and particle size were optimized separately; therefore, they allowed the targeting of a certain class of compounds only by varying the spray drying process parameters. Yet, the desirability function in the RSM was utilized to reveal the combination of the parameters (maltodextrin and carrageenan gum concentration) which are capable of simultaneously maximizing or minimizing the responses. The overplay plot shows the outlines superposition of all the studied responses and the simultaneous optimum for all responses is shown by the black spot (Figure 5) showing the best experimental parameters that maximize bioactive compounds content and minimize powder product characteristics. The black spot showed the optimum for all the responses.

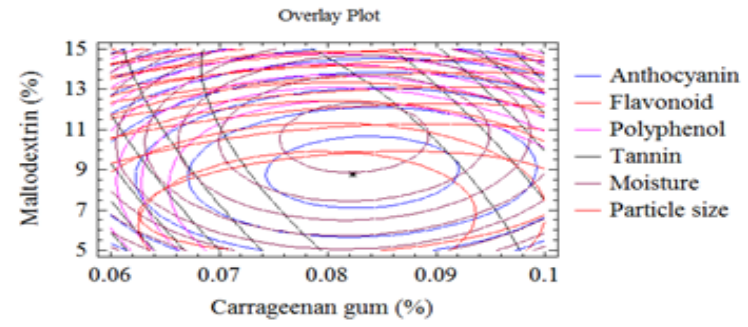

Figure 5. Superposition plots. 


\section{Conclusion}

The effects of the concentration of maltodextrin and carrageenan gum on the powder quality of the spray dried Pouzolziazeylanica extract had successfully been investigated by factorial experimental design. The result of simultaneous optimum for all responses showed that the optimum supplemental carrier concentrations to produce spray dried powder with the highest content of bioactive compounds, the lowest moisture content and the smallest particle size were obtained when the blending of maltodextrin and carrageenan gum concentration was $8.8 \%$ and $0.082 \%$, respectively.

\section{References}

Abadio, F. D. B., Domingues, A. M., Borges, S. V., \& Oliveira, V. M. (2004). Physical properties of powdered pineapple (Ananas comosus) juice effect of maltodextrin concentration and atomization speed. Journal Food Engineering 64(3), 285-287.

Ahmed, J. K., Salih, H. A. M., \& Hadi, A. G. (2005). Anthocyanins in red beet juice act as scavengers for heavy metals ions such as lead and cadmium. International Journal of Science and Technology 2(3), 269-274.

Bhusari, S. N., \& Kumar, P. (2014). Antioxidant activities of spray dried tamarind pulp powder as affected by carrier type and their addition rate. International Conference on Food, Biological and Medical Sciences (FBMS-2014), Bangkok (Thailand).

Burey, P., Bhandari, B. R., Howes, T., \& Gidley, M. J. (2008). Hydrocolloid gel particles: Formation, characterization, and application. Cirtical Reviews in Food Sciences and Nutrition 48(5), 361-377.

Eswari, M. L., Bharathi, R. V., \& Jayshree, N. (2013). Preliminary phytochemical screening and heavy metal analysis of leaf extracts of Ziziphus oenoplia (L) Mill. Gard. International Journal of Pharmaceutical Sciences and Drug Research 5(1), 38-40.

Favano, T. C. S., Santana, A. S., Monterrey, Q. E. S., Trindade, M. A., \& Netto, F. M. (2010). The use of spray drying technology to reduce bitter taste of casein hydrolysate. Food Hydrocolloids 24(4), 336-340.

Fernandes, L. P., Candido, R. C., \& Wanderley, P. O. (2012). Spray drying micro-encapsulation of Lippia sidoides extracts in carbohyrate blends. Food and Bioproducts Processing 90(3), 425-432.

Fu, M., Niu, Y. Y., Yu, J., \& Kong, Q. T. (2012). Study on the chemical constituents in Pouzolzia zeylanica. Zhong Yao Cai 35(11), 1778-17781.

Ghani. (2003). Medicinal plants of Bangladesh: Chemical constituents and uses ( $2^{\text {nd }}$ ed.). Dhaka, Bangladesh: The Asiatic Society of Bangladesh.
Goula, A. M., Adamopoulos, K. G., \& Kazakis, N. A. (2004). Influnce of spray drying conditions on tomato powder properties. Drying Technology 22(5), 11291151.

Goula, A. M., \& Adamopoulos, K. G. (2005). Spray drying of tomato pulp in dehumidified air. II. The effect on powder properties. Journal of Food Engineering 66(1), $35-42$.

Grabowski, J. A., Truong, V. D., \& Daubert, C. R. (2006). Spray drying of amylase hydrolyzed sweet potato puree and physicochemical properties of powder. Journal of Food Science 71(5), 209-217.

Guan, X., \& Yao, H. (2008). Optimization of viscozyme L assisted extraction of oat bran protein using response surface methodology. Food Chemistry 106(1), 345-351.

Hossain, M.A., Raqmi, K. A. S., Mijizy, Z. H., Weli A. M., \& Riyami, Q. (2013). Study of total phenol, flavonoids contents and phytochemical sreening of various leaves crude extracts of locally grown Thymus vularis. Asian Pacific Journal of Tropical Biomedicine 3(9), 705-710.

Kha, T. C., Nguyen, M. H., \& Roach, P. D. (2010). Effects of spray drying conditions on the physicochemical and antioxidant properties of the Gac (Momordica cochinchinensis) fruit aril powder. Journal of Food Engineering 98(3), 385-392.

Laitonjam, W. S., Yumnam, R., Asem, S. D., \& Wangkheirakpam, S. D. (2013). Evaluative and comparative study of biochemical, trace elements and antioxidant activity of Phlogacanthus pubinervius T. Anderson and Phlocanthus jenkincii C.B. Clarke leaves. Indian Journal of Natural Products and Resources $4(1), 67-72$.

Langrish, T. A. G., Chan, W. C., \& Koda, K. (2007). Comparison of maltodextrin and skim milk wall deposition rates in a pilot-scale spra dryer. Powder Technology 179(1-2), 83-89.

Le, T. T. (2007). Preliminary test of chemical components for Pouzolzia zeylanica L. Benn. (Unpublished Chemical master's thesis). University of Natural Science, HCM city, Vietnam.

Mandal, S., Patra, A., Samanta, A., Roy, S., Mandal, A., Mahapatra, T. D., Pradhan, S., Das, K., \& Nandi, D. K. (2013). Analysis of phytochemical profile of Terminalia arjuna bark extract with antioxidative and antimicrobial properties. Asian Pacific Journal of Tropical Biomedicine 3(12), 960-966.

Martineli, L., Gabas, A. L., \& Telis, R. J. (2007). Thermodynamic and quality properties of lemon juice powder as affected by maltodextrin and arabic gum. Drying Technology 25(12), 2035-2045.

Masniza, M., Hani, I. M. H., Farah, S. H., \& Rinani, S. A. R. (2013). Maltodextrin encapsulation of Garcinia atroviridis Griff by spray drying technique. International Journal of Scientific Engineering and Technology 2(10), 1011-1012. 
Myers, R. H., Montgomery, D. C., \& Anderson-Cook, C. M. (2009). Response surface methodology: process and product optimization using designed experiments. Wiley: New York.

Ochoa-Martinez, L. A., Garza-Juarez, S. E., Rocha- Guzman, N. E., Moraies-Castro, J., \& Gonzalez-Herrera, S. M. (2015). Functional properties, color and betala in content in beetroot-orange juice powder obtained by spray drying. Journal of Food and Dairy Technology $3(2), 30-36$.

Oktay, M., \& Kufrevioglu, I. (2003). Determination of in vitro antioxidant activity of fennel (Foeniculum vulgare) seed extract. LWT 36(2), 263- 271.

Sabhadinde, V. N. (2014). The physicochemical and storage properties of spray dried orange juice powder. Indian Journal of Fundamental and Applied Life Science 4(4), 153-159.

Saha, D., \& Paul, S. (2012). Studies on Pouzolzia zeylanica (L.) Benn. (Family: Urticaceae). Oxford, United Kingdom: Blackwell.

Sansone, F., Mencherini, T., Picerno, P., Amore, M. D., Aquino, R. P., \& Lauro, M. R. (2011). Maltodextrin/pectin microparticles by spray drying as carrier for nutraceutical extracts. Journal of Food Engineering 105(3), 468-476.

Santana, A., Kuroxawa, L., Oliveria, R., \& Park, K. (2016). Spray drying of pequi pulp: process performance and physicochemical and nutritional properties of the powdered pulp. Brazlian Archives of Biology and Technology 59, 1-11.

Santos, D. T., Cavalcanti, R. N., Rostagno, M. A., Queiroga, C. L., Eberlin, M. N., \& Meireles, M. A. A. (2013). Extraction of polyphenols and anthocyanins from the Jambul (Syzygium cumini) fruit peels. Food and Public Health 3(1), 12-20.

Sarabandi, K., Peighambardoust, S. H., \& Shirmohammadi, M. (2014). Physical properties of spray dried grape syrup as affected by drying temperature and drying aids. International Journal of Agriculture and Crop Sciences 7(12), 928-934.

Shari, A., Niakousari, M., Maskooki, A., \& Mortazavi, S. A. (2015). Effect of spray drying conditions on the physicochemical properties of barberry (Berberis vulgaris) extract powder. International Food Research Journal 22(6), 2364-2370.

Shishir, M. R. I., Tuip, F. S., Aziz, N. A., Taih, R. A., \& Safulah, M. (2015). Effect of maltodextrin concentrations at different drying temperatures on the physical and drying properties of the spray dried pink guava powder. Journal of Applied Science and Agriculture 10(5), 176-182.
Singh, V. K., Pandey, S., Pare, A., \& Singh, R. B. (2014). Optimization of process parameters for the production of spray dried Ber (Ziziphus jujube L.) powder. Journal Food Science Technology 51(12), 3956-3962.

Spigno, G., Tramelli, L., \& De-Faveri, D. M. (2007). Effects of extraction time, temperature and solvent on concentration and antioxidant activity of grape marc phenolics. Journal of Food Engineering 81(1), 200-208.

Tee, L. H., Lugman, C. A., Pin, K. Y., Addull, R. A., \& Yusof, Y. A. (2012). Optimization of spray drying process parameters of Piper betle L. (Sirih) leaves extract coated with maltodextrin. Journal of Chemical and Pharmaceutical Research 4(3), 1833-1841.

Tonon, R. V., Brabet, C., \& Hubinger, M. D. (2008). Influnce of process conditions on the physicao- chemical properties of Acai (Euterpe Oleraceae Mart.) powder produced by spray drying. Journal of Food Engineering 88(3), 411-418.

Tran, T. M., Nguyen, H. T. T., Duong, N. T. M., Tran, L. C., \& La, K. V. (2010) (2010). Experimental study on some pharmacological effects of Pouzolzia zeylanica and Tinospora crispa. Medicine Journal of Ho Chi Minh city, Special Subject Traditional Medicine 14 (2), 116-120.

Tsai, C. W., Tong, L. I., \& Wang, C. H. (2010). Optimization of multiple responses using data envelopment analysis and response surface methodology. Tamkang Journal of Science and Engineering 13(2), 197-203.

Vo, C. V. (2012). Dictionary medicinal plants in Vietnam. Ha Noi, Viet Nam: Medicine Publishing House.

Wang, W., \& Zhou, W. (2013). Effect of maltodextrin on water adsorption and glass transition of dried soy sauce powder. Food and Bioprocess Technology. Doi:10.1007/5 11947-012-0992-5.

Wangensteen, H., Samuelsen, A. B., \& Malterud, K. E. (2004). Antioxidant activity in extracts from coriander. Food Chemistry 88(2), 293-297.

Zabeti, M., Daud, W. M. A., \& Aroua, M. K. (2009). Optimization of the activity of $\mathrm{CaO} / \mathrm{Al}_{2} \mathrm{O}_{3}$ catalyst for biodiesel production using response surface methodology. Applied Catalysic A: General. 366(1), 154-159. 